\title{
O sujeito na mídia: do opaco ao notório Uma visão sobre a formação do jornalismo e seu reflexo na prática ${ }^{1}$
}

\author{
The subject in the media: from opaque to the notorious \\ An insight into the formation of journalism and its reflection in practice \\ El individuo en los medios: lo opaco a la notoria \\ Una idea de la formación del periodismo y su reflejo en la práctica
}

Priscilla Guerra Guimarães Bernardes ${ }^{2}$

\begin{abstract}
Resumo
O presente artigo fundamenta-se numa leitura crítica da mídia feita em diversas peças jornalísticas publicadas pela mídia tradicional, que descortinam um processo de produção de notícias pasteurizado que é frequentemente ensinado nas salas de aulas dos cursos de Jornalismo e que desemboca na realidade dos veículos e dos profissionais que utilizam normas e padrões valorativos na construção da notícia e antagônicos em questões sociais e humanísticas. A principal dissonância entre critérios de noticiabilidade como a notoriedade que corrobora para a opacidade do sujeito, esmaecendo alguns em razão de outros tidos como mais relevantes por serem atrativos noticiosos de maior destaque.
\end{abstract}

Palavras-chave: Antropologia. Comunicação. Jornalismo.

\begin{abstract}
This article is based on a critical media made in several news stories published by traditional media that arise pasteurized news production process that is often taught in the classrooms of journalism courses and flows into the reality of vehicles and of professionals who use norms and value patterns in the construction of news on antagonistic social and humanistic issues. The main dissonance between newsworthiness criteria as the notoriety that confirms the opacity of the subject, some fading due to other seen as most relevant for being the most outstanding news attractions.
\end{abstract}

Keywords: Anthropology. Communication. Journalism.

\section{Resumen}

\footnotetext{
${ }^{1}$ Este trabalho foi desenvolvido dentro do Projeto de Pesquisa Rupturas Metodológicas para uma leitura crítica da Mídia entre os Programas de Pós-Graduação da UFG e UFRJ, que integra a ação transversal nº 06/2011 - Casadinho/Procad. A confecção do artigo teve como objetivo a composição da base avaliativa da disciplina de Antropologia e Comunicação, ministrada pela professora Dra. Luciene de Oliveira Dias.

${ }^{2}$ Mestranda do Programa de Pós-graduação em Comunicação da Faculdade de Informação e Comunicação da Universidade Federal de Goiás (UFG). Especialista em Marketing e Comunicação Digital pela Faculdade Cambury. Graduada em Jornalismo pela Pontifícia Universidade Católica de Goiás (PUC-GO). E-mail: priscillaguerra@hotmail.com
}

Comun. \& Inf., Goiânia, GO, v. 18, n. 02, p. 217-235, jul./dez. 2015

Caderno Casadinho Procad UFG-UFRJ 
Este artículo se basa en una crítica de los medios realizado en varias noticias publicadas por los medios de comunicación tradicionales, que surgen proceso de producción de noticias que a menudo se enseña en las aulas de los cursos de periodismo y desemboca en la realidad de los vehículos y pasteurizada de profesionales que utilizan las normas y patrones de valor en la construcción de las noticias y los temas sociales y humanísticas antagónicos. La principal disonancia entre los criterios de interés periodístico como la notoriedad que confirma la opacidad de la materia, algunos desvanecimiento debido a otra vista como más relevante por ser las atracciones noticias más destacadas.

Palabras clave: Antropología. Comunicación. Periodismo.

\section{INTRODUÇÃO}

abe-se que a comunicação enquanto campo possui um estatuto amplamente
marcado pela interdisciplinaridade e de terreno abrangente. Por tratar-se de um
campo em construção como defendem diversos teóricos, se fundamenta em fontes sociológicas, filosóficas, sociais, históricas, antropológicas e assim por diante em diversas outras ciências com as quais dialoga. A miscelânea de autores, teorias e conhecimentos das diversas áreas que compõe a comunicação acaba por também constituir boa parte das ciências sociais propriamente ditas. Propriamente dita uma vez que Santos (1989), em seu texto sobre a Crítica da Razão Indolente, defende o princípio de que toda ciência é social, independentemente de seu objeto ou método, uma vez que só ganha sentido e validade se contribuir de algum modo para a sociedade.

Neste sentido, o autor nos leva a pensar que o objetivo de promover a simbiose entre disciplinas seja no intuito de aprimorar as práticas para cada vez mais incidir numa sociedade em evolução. As trocas entre os variados campos com a comunicação são quase sempre acirradas, outrora se parecem disputas e a busca por um denominador comum parece um desafio para aqueles que procuram um equilíbrio entre os conceitos e conclusões.

Quando se tenta encontrar a convergência entre o campo da comunicação e o campo da antropologia por exemplo, diversas resistências se apresentam por parte daqueles que as estudam. Lago (2003) ao tratar desta tentativa de intersecção e de suas dificuldades menciona a distinção entre os fazeres e principalmente entre os olhares.

Antropologia, com uma tradição de autorreflexão sobre suas práticas (ampliada pela necessidade de adequar seu método a objetos diferentes do tradicional),

Comun. \& Inf., Goiânia, GO, v. 18, n. 02, p. 217-235, jul./dez. 2015

Caderno Casadinho Procad UFG-UFRJ 
geralmente garante espaços em suas pesquisas para analisar as relações em que se efetiva seu fieldwork. Já a comunicação, com reflexões esparsas e difusas, parece-me pouco incorporar desse tipo de reflexão (LAGO, 2003, p.6-7).

O enfrentamento teórico entre a Antropologia e a Comunicação esbarra numa dificuldade filosófica que duela desde o princípio, quando é proposta nos cursos de formação de comunicadores. A existência obrigatória do módulo de Antropologia na grade de Jornalismo poderia soar a grosso modo como uma apropriação dos referenciais teóricos da Antropologia dentro da construção do profissional de Comunicação. O objetivo formal certamente se configura neste sentido, porém, a batalha conceitual se estende desde o exercício acadêmico de estudo destas matérias até alcançar a sociedade, por meio do profissional formado nessa dicotomia que edificará discursos e construirá um imaginário social, ou em termos diferentes, uma opinião pública.

Importante mencionar que a opinião pública reverenciada neste trabalho foge da obviedade do conceito de opinião do público, e se coloca do mesmo modo que a cultura de massa. Assim como a cultura de massa representa a cultura produzida para a massa, a opinião pública também se caracteriza como a opinião produzida para o público. (BRAGA; TUZZO, 2009)

Dentro da noção desta opinião pública, admite-se que atualmente lidamos com uma centralidade midiática nas sociedades, onde a arena de debates e conteúdo é majoritariamente produzida e transmitida pela mídia de acordo com seus critérios de seleção e recorte. Neste sentido, o jornalista caracteriza-se como um formador de opinião pública e seu papel no funcionamento da sociedade ultrapassa o ato de emissão da palavra, chegando a recepção e reverberação de crenças, ideias, fatos, opiniões e assim por diante.

O conflito da formação do profissional também inquieta Dias (2014) que questiona a credibilidade mítica que impera ao jornalismo como espaço de fala amplo, mas que na prática apenas pasteuriza o processo noticioso e garante a manutenção dos privilégios, o silenciamento dos subalternos e o vigente status quo. Segundo a autora, a formação acadêmica dos profissionais corrobora para a reprodução deste modelo, e pouco espaço confere para celebrar a diferença, a alteridade e insurgir em mudanças sociais necessárias.

Um aluno de Jornalismo durante seu curso contará com instruções de Teorias do 
Jornalismo e Produção de Notícias para exercer a prática cotidiana elegendo acontecimentos noticiáveis de modo ágil, produtivo e com maior chance de ser bem sucedido enquanto notícia de interesse público no sentido de compra. Para tanto, lhe serão ensinados quais os critérios de noticiabilidade que mecanizarão o reconhecimento do fato de destaque, bem como a construção do lead, escolha das fontes e outros diversos métodos e técnicas jornalísticas.

Os critérios de noticiabilidade são oriundos de uma noção maniqueísta da prática comunicativa que surgem para auxiliar o profissional a hierarquizar e assim selecionar e enquadrar os eventos sociais a serem reportados publicamente independentemente do veículo. O foco do objetivo mercadológico da empresa jornalística recebe o profissional formado com as competências mecânicas de reprodução e ao exigir lucro e rendimento intelectual, exime a reflexão sobre a prática exercida e a busca por uma imprensa mais articulada e com anseios sociais e humanos.

A premissa base da visão da noticiabilidade é a tentativa de sistematizar a sociedade, generalizar os fatos e montar fórmulas de conteúdos com potencial para aguçar a curiosidade do interlocutor. O celeuma em relação a Antropologia é exatamente este: a base do trabalho que destoa por completo da vocação antropológica.

O olhar do antropólogo contempla a especificidade, a ausência de padronizações e a procura pelo diferente, não enquanto exótico ou bizarro, mas enquanto forma de vida e existência na tentativa de garantir espaço no meio onde vive tendo o direito de conviver sendo diferente como direitos e deveres de qualquer outra pessoa. Se para o comunicador existe um fato de maior valor do que outro, ou mesmo uma fonte, ao antropólogo não cabe arriscar uma sobreposição de fatos já que este verifica as conjunturas e se coloca a enxergar que cada acontecimento tem sua repercussão social única.

Neste sentido, este trabalho pretende fazer uma leitura crítica da mídia que possa pontuar a ausência de um olhar antropológico no espaço noticioso e seu respectivo efeito ceifador e ofuscador de sujeitos, além de refletir sobre a estrutura de formação acadêmica do profissional midiático que mesmo apresentando certa abertura à autorreflexão promove a continuidade da cultura jornalística que detrime pessoas e fatos dentro da sociedade. 


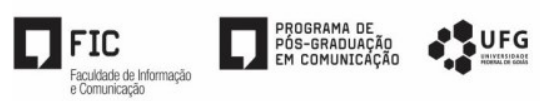

\section{COMUNICAÇÃO, CULTURA E CIDADANIA: SEPARADOS NA MATERNIDADE}

De modo inegável, a comunicação costurou o elo entre estas sociedades e o desenvolvimento atravessado por elas ao longo do tempo. Neste sentido, a própria administração e organização das atividades, a divisão de tarefas, territórios e até mesmo as noções básicas de ética e moral foram propostas através da transmissão de conteúdos comunicados entre os habitantes de determinado grupo, num processo de elaboração cultural.

A noção de cultura nasce no ser humano a partir da constituição das sociedades primitivas e da partilha de símbolos apropriados por um determinado povo. Como afirma Laraia (2006) as características humanas são comuns a toda espécie e apenas seus traços culturais, seus hábitos é que são capazes de diferenciá-los entre si e entre outros agrupamentos humanos.

Gorzeviscki e Martin (2011) chamam atenção para a ênfase dada a determinados indivíduos dentro dos grupos, que passavam a ser mais respeitados e seguidos em razão de suas características de influência e segurança ofertada ao grupo. Com o passar do tempo, estas figuras incumbidas de liderar os demais habitantes perderam espaço para outras cujo potencial não se tratava de habilidades físicas mas migrava para a influência daqueles com expressiva habilidade de fala.

Os talentos orais se elevam em diversas sociedades compondo a noção de cultura de diversos povos e sendo a responsável por manter as tradições e crenças de determinado povo. Os ideais religiosos e familiares florescem na explanação daqueles que se diziam intermediários entre o plano terreno e o metafísico, onde estavam os questionamentos e boa parte das normativas sociais justificadas.

Nas Idades Média e Moderna o monopólio da fala vive a dicotomia Estado-Igreja como pontua Morgado (2005), sendo essas duas instituições sociais as responsáveis por determinar as crenças populares e por exercer controle sobre o que pensavam os cidadãos de determinada cidade ou feudo. A autora menciona que essa polarização discursiva na sociedade apenas se rompe quando outros indivíduos, munidos de habilidades orais e de boa desenvoltura pública, tomam conhecimento de assuntos restritos à igreja ou à monarquia e, assim, começam a exercer influência ao incluir novos posicionamentos dentro das comunidades.

Gorzevscki e Martin (2011) verificam neste momento o início das mudanças na 
concepção de cidadania, uma vez que os líderes de opinião passam a exercer pressão por melhorias sociais e mais direitos. Foi o caso de John Locke e sua influência expressiva no entendimento da propriedade privada, de Immanuel Kant com a aplicabilidade das leis, Marx e a compreensão da relação trabalhista e dos direitos operários e assim por diante.

Morgado (2005) não deixa de defender a invenção da imprensa como catalisadora neste processo. Em sociedades com maior contingente populacional, não era eficiente que os líderes de opinião só pudessem exercer influência nos cafés. Com os tipos móveis foi possível criar panfletos e folhas volantes que alcançavam um maior número de pessoas, valendo dizer que neste período a invenção da imprensa contribui para o aumento da publicação de livros e para a redução do analfabetismo.

A figura do jornalismo desmonta a hegemonia político-religiosa e mobiliza a sociedade ao funcionar como a terceira via pública de expressão e força. Rapidamente esta imprensa que rompe esta dicotomia, entra no campo discursivo sendo o lado mais centralizado do tripé comunicativo de determinada sociedade.

Evidentemente, a centralidade midiática passa a ser percebida como potencial capitalista e como fonte de renda e lucro, e aos poucos começa a objetivar com maior foco o lucro, requerendo técnicas e formatos para produzir notícias e conteúdo de interesse público, sempre na ânsia de vender mais jornais e revistas. Nasce por esta razão o modus operandi do jornalista ou as coordenadas e diretrizes de trabalho.

Assim que o jornalismo se firmou como uma atividade comercial dentro das sociedades, os primeiros proprietários perceberam que determinadas notícias apresentavam maior procura dos leitores, e assim, começaram a investir nestes temas visando atrair maior demanda de consumo e garantir maiores lucros para a empresa.

Wolf (2001) comenta que a fabricação dos critérios de noticiabilidade partiu da própria experiência das redações, evidentemente em decorrência de fatores culturais, e assim passou a nortear o trabalho dos jornalistas para que perseguissem temas com maior coeficiente de curiosidade, o que nem sempre significavam avanços para a cidadania como ocorreu no preâmbulo da imprensa.

A partir deste breve contexto histórico, vale compreender que a comunicação, a cidadania e a cultura que nasceram juntas, foram colocadas em âmbitos separados, algumas vezes até em 


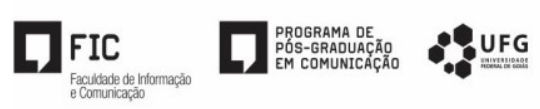

oposição. Ao perceber uma comunicação que exclui cidadãos ou que pontua quais são os mais relevantes é possível perceber um severo abismo em relação à cidadania com seus diversos princípios de integração e direitos.

\section{DAS TEORIAS DO JORNALISMO PARA A PRÁTICA DAS REDAÇÕES}

Como colocado anteriormente o jornalismo passou por etapas de evolução até chegar ao nível em que se apresenta atualmente. Vale ressaltar que o crescimento populacional acionou válvulas de criatividade e inovação para os profissionais deste meio que precisaram se adaptar a grandes públicos, à concorrência de outros veículos e para isto precisaram aperfeiçoar as técnicas e fazer uma reflexão mais profunda sobre as condutas da profissão e a confecção do produto noticioso.

Disciplinas como Teoria do Jornalismo são elencadas na grade de jornalismo para difundir as muitas compreensões sobre a lógica do exercício noticioso, o que inclui entre outras o estudo dos critérios de noticiabilidade (ou valores-notícia), o agendamento e a teoria da espiral do silêncio.

De forma ampla, podemos destacar em todo este processo o surgimento de estudos quantitativos e qualitativos feitos sobre todos os veículos, que procuravam fazer uma leitura do público, com o intuito de compreender o que esse público buscava, o que lhe interessava mais e o que de fato as pessoas precisavam ler/assistir/ouvir. Foi então que se procurou entender quais eram os valores-notícia que mais despertavam atenção das pessoas.

Traquina, apoiando-se nos estudos de Tuchman, criou a seguinte definição a respeito:

Podemos definir o conceito de noticiabilidade como um conjunto de critérios e operações que fornecem a aptidão de merecer um tratamento jornalístico, isto é, possuir valor como notícia. Assim os critérios de noticiabilidade são um conjunto de valores-notícia, que determinam se um acontecimento ou assunto, é susceptível de se tornar notícia, isto é, de ser julgado como merecedor de ser transformado em matéria noticiável e, por isso, possuindo valor-notícia (TRAQUINA, 2005, p. 63).

Entre os diversos critérios próprios da notícia, é possível ressaltar a morte, o insólito, o conflito, o interesse nacional, a falha, a relevância, a novidade, a proximidade geográfica ou

Comun. \& Inf., Goiânia, GO, v. 18, n. 02, p. 217-235, jul./dez. 2015

Caderno Casadinho Procad UFG-UFRJ 


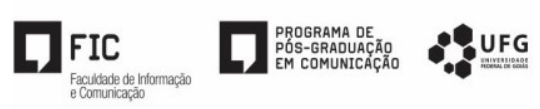

cultural, e ainda a notoriedade. Todos estes valores-notícia são de algum modo uma forma de pasteurizar as informações e de massificar a sociedade. Não sendo essencial tratar especificamente um por um, se grifam os dois últimos como maiores exemplos do caráter cerceador desta teoria.

Ao falar do critério de noticiabilidade conhecido como proximidade geográfica ou cultural se entende a proximidade ou distância de determinadas razões que por estarem localizadas próximas às outras ou por apresentarem traços culturais (o que inclui elos financeiros) possuem maior representatividade enquanto notícia. Neste caso é possível verificar que o aspecto cultural ou mesmo o significado financeiro e diplomático de determinados países consegue ser visto como mais impactante do que um profundo tormento num espaço vizinho

$\mathrm{O}$ outro aspecto (e mais intrigante entre os demais) é o que Galtung e Ruge (apud TRAQUINA, 2005) entendem com o envolvimento de um ator principal de um acontecimento. A celebridade ou a importância hierárquica dos indivíduos que protagonizam o acontecimento são facilmente imbuídos no rol de notícias importantes. Para os autores esse elemento de percepção também é chamado de personalização da notícia. Segundo os autores, "quanto mais o acontecimento disser respeito às pessoas de elite, mais provavelmente será transformado em notícia“ (apud TRAQUINA, 2005, p. 80).

Em síntese, se quer dizer que personalidades-chaves, pessoas públicas quando envolvidas em acontecimentos a serem noticiados, conferem maior interesse público, o que também pode ser chamado de proeminência, ou o que Wolf (2001) chama de importância hierárquica. Esta importância hierárquica dos atores do fato pode ser referente à importância política, social ou econômica de pessoas ou nações.

O próprio Canevacci (2004) traz na contramão o conceito de opacidade do sujeito ao falar da suposta invisibilidade dos sujeitos mediante os contextos sociais, e de modo quase linear, abrange sem mencionar a mídia como entidade fomentadora deste fenômeno nocivo e que provoca atrasos à cidadania e a vivência humana, especialmente pela ausência da polifonia percebida nas práticas midiáticas.

Paralela às considerações de Canevacci (2004), ressoa a pesquisa executada pelo pesquisador da USP, Fernando Braga Costa (2002), que investigou as reações sociais frente a indivíduos que estivessem em posição de invisibilidade, conforme chamou. Em seu trabalho, 


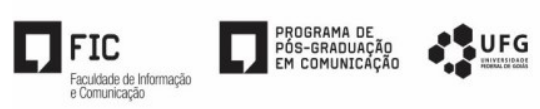

Braga concluiu que determinadas profissões se não estiverem atreladas a um imaginário de poder e riqueza são automaticamente desprezadas, especialmente se lançam mão do uso de uniformes.

A experiência de Costa (2002) reflete sobre a familiaridade dada ao comportamento excludente dentro da sociedade, que segrega no próprio tratamento social pessoas por condições sociais por exemplo.

Para demarcar a gravidade desta cultura jornalística este trabalho fará uma exposição de diversas peças noticiosas constituídas por estes elementos enquanto notícia, e analisará o impacto, do ponto de vista antropológico, na opinião pública colocada pelos veículos e distribuída na sociedade e no entendimento do público que consome estes critérios como verdadeiros filtros de percepção dos demais.

\section{METODOLOGIA}

Este trabalho partiu de uma leitura crítica da mídia realizada em fatos publicados na imprensa nacional, escolhidos em épocas e jornais aleatórios e variados, para verificar a existência do critério de noticiabilidade conhecido como notoriedade, visando explorar suas possíveis implicações sociais.

Os fatos selecionados se caracterizam pela presença da notoriedade inserida nos fatos, em notícias com personalidades tidas como importantes e de maior destaque. São eles: um acidente automobilístico envolvendo o filho do cirurgião plástico Ivo Pitangui, a queda da aeronave que levava os apresentadores de televisão Luciano Huck e Angélica, a queda do helicóptero que levava o filho do governador Geraldo Alckmin e a queda fatal do avião do presidenciável Eduardo Campos. Todos os eventos foram investigados na versão online de pelo menos três veículos impressos ou televisivos para buscar uma aproximação entre o modo de atuação jornalística.

\section{A NOTORIEDADE DA NOTÍCIA E A OPACIDADE DOS SUJEITOS ENVOLVIDOS}

Como colocado anteriormente a mídia, englobando os inúmeros veículos e formatos comunicativos, contribui de modo intrínseco para a composição da cultura de determinada sociedade, que como já postulava Laraia (2006) trata-se de um processo dinâmico, em constante metamorfose. Nesse sentido a ideia de ler notícias é basicamente a busca pela compreensão de 
quais fatos sociais são difundidos dentro da sociedade, reverberando uma opinião pública e delineando os traços culturais que norteiam determinada coletividade.

Ao investigarmos na imprensa matérias cujo valor-notícia é circulado pela personalização ou notoriedade se encontram diversos exemplos sem qualquer dificuldade, uma vez que a compreensão do célebre já é algo corriqueiro e marcante. Tuzzo e Figueiredo (2011) já dimensionavam esse traço e afirmavam que a valorização do célebre no espaço social se tornou tão expressivo e cultuado que criou nos cidadãos a necessidade de buscar os holofotes a qualquer custo, garantindo exposição na mídia, fama e o status de reconhecimento que atribuem aos notáveis. As autoras destacam a entronização do processo de reconhecimento público, afirmando que esta passa a representar uma virtude socialmente admirada.

Para este trabalho selecionamos algumas notícias de repercussão nacional, cujo fator de maior destaque era a presença de alguma figura ilustre ou com alto teor de reconhecimento público. O primeiro exemplo foi a queda do avião que matou o presidenciável, Eduardo Campos em agosto de 2014, juntamente com outros seis integrantes, incluindo membros da equipe política do candidato, além de piloto e copiloto.

Ao buscar a matéria nos três maiores jornais impressos de circulação no país (Folha de São Paulo, $O$ Estado de São Paulo e $O$ Globo) o título que se encontrou anunciava a queda do avião e a morte do governador. Os demais passageiros da aeronave foram citados dentro do texto da notícia como informações complementares, ao contrário do enfoque dado ao presidenciável cujas informações eram completas, e explicavam até a desistência da esposa do candidato de embarcar no avião em razão de outros compromissos. As imagens que ilustravam a matéria estampavam o rosto de Eduardo Campos, e se percebe até certa exaltação de seu caráter trabalhador e determinado em seus objetivos de campanha.

Muitas outras suítes ${ }^{3}$ foram produzidas por estes veículos (e possivelmente por outros) com a cobertura do velório, do luto da viúva de Eduardo Campos e dos filhos e principalmente sobre quais seriam as intercorrências da morte do candidato em véspera das eleições juntamente com a figura de sua então vice Marina Silva. A procura por fontes nas matérias que anunciavam a morte e que comentavam os fatos sequenciais eram praticamente todos envolvidos ao

\footnotetext{
${ }^{3}$ Formato de reportagem que explora os desdobramentos de uma notícia.
} 


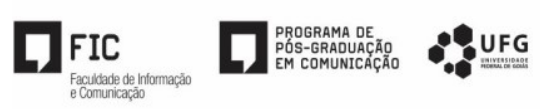

presidenciável, e a respeito do foco dado a viúva de Campos, surgiram muitas matérias elevando seu papel enquanto companheira do político, sua árdua tarefa com os cinco filhos e o possível engajamento nas eleições ao lado de Marina Silva.

Não se procurou ouvir e documentar a história, os familiares, o luto e o contexto que envolveu os outros passageiros do vôo. Sobre os demais passageiros os únicos dados divulgados foram nomes, idade, estado civil e profissão. O lado sentimental explorado até de modo demasiado e abusivo ficou restrito aos envolvidos notórios, os outros se restringiram a burocracia da citação e da composição do lead.

O segundo caso separado como exemplo nesta análise trata-se de outro acidente aéreo, desta vez envolvendo a queda de um helicóptero que vitimou Thomaz Alckmin, filho do governador de São Paulo, Geraldo Alckmin, e outras cinco pessoas que estavam a bordo. Neste caso em particular o furo foi dado por diversos veículos antes da identificação dos corpos. Assim que as identidades foram reveladas, novamente a imprensa se antecipou em retificar o texto e noticiar que não se tratava de um helicóptero qualquer a cair na região metropolitana paulista, mas a aeronave que levava o filho do governador do Estado, que morria a partir dali sozinho nos títulos noticiados pela imprensa.

A partir do momento da divulgação da morte de Thomaz Alckmin uma busca frenética apareceu na imprensa de todo país, para relatar o posicionamento e o pesar do governador de São Paulo e da primeira-dama Lu Alckmin. Notícias sobre o velório, sobre a filha mais velha de Thomaz que vivendo com a mãe na França era esperada para o enterro do pai, imagem dos irmãos, políticos e celebridades se manifestando em redes sociais sobre a pessoa de Thomaz, além de informações sobre o enterro que seguiu em local exclusivo e separado dos demais passageiros, contando com incansável cobertura jornalística, além de atrair com as notícias, centenas de pessoas que se dirigiram ao local do enterro para dizer adeus ao filho caçula de Alckmin, no mesmo momento em que os demais integrantes do acidente eram enterrados sem qualquer audiência ou exposição de detalhes que viessem a interessar.

Um terceiro caso trata-se de um acidente automobilístico envolvendo outro filho de personalidade célebre. Herdeiro do renomado cirurgião plástico Ivo Pitanguy, o também Ivo 


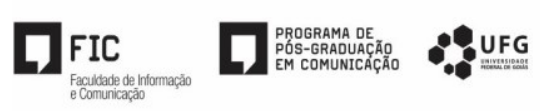

Pitanguy colidiu seu veículo utilitário com o funcionário do metrô de São Paulo, José Ferreira da Silva. De acordo com a perícia, o empresário estava alcoolizado e já havia se envolvido em outros acidentes de trânsito anteriormente.

Em todos os casos averiguados a cobertura utilizou o nome do empresário no título da matéria, apresentando apenas dentro do texto, como complemento a descrição da vítima fatal, contendo o nome, profissão, idade e uma foto 3x4. A Redetv em sua versão online reproduziu a cobertura dada ao acontecimento, incluindo a morte como um detalhe irrisório no predicado da informação. Ao mencionar "Filho de cirurgião se envolve em acidente com um morto no RJ", numa leitura da língua portuguesa o operário não se enquadra nem no sujeito ou predicado, sendo apenas uma informação extra sobre o fato que basicamente era um acidente com o filho de um dos cirurgiões mais famosos do país.

O curioso é que a morte do operário dentro do texto foi escrita com menos relevância do que o traumatismo craniano que levou o empresário a ser internado num hospital carioca, havendo portais que deram informações sobre o estado de saúde do mesmo e até sobre as consequências penais de sua "infração". Em uma das suítes do caso, o advogado de Pitanguy ganhou voz para defender o empresário, afirmando que o pouco dano no veículo indicavam velocidade moderada e assim a amortização da pena.

Um último exemplo reproduz novamente a notoriedade como bússola cognitiva das notícias de destaque. Trata-se do pouso forçado que teve de ser feito com o avião que levava os apresentadores Luciano Huck, Angélica, filhos e suas babás. De modo similar às outras notícias citadas ou ainda àquelas que tratam de personalidades famosas, o título apenas mencionou as duas figuras reconhecidas e seus filhos. No interior da notícia, o nome das crianças foi revelado, assim como dos pilotos e a descrição das babás sequer mencionou o nome das mesmas, idade ou qualquer outra informação a respeito de ambas. O casal Huck ao desembarcar em Mato Grosso, foi encaminhado para um hospital público onde relativo caos se instaurou ao receberem atendimento prioritário, desrespeitando a fila de atendimentos do SUS naquela data.

Nesta notícia, percebe-se o extremo desleixo por parte de todos os veículos verificados por não colocarem sequer a identificação das funcionárias. Todavia, nas redes sociais este fato repercutiu de modo instigador. Unido ao fato do casal ter sido atendido prioritariamente num hospital público com seus filhos, a ausência do nome das babás provocou indignação nos 


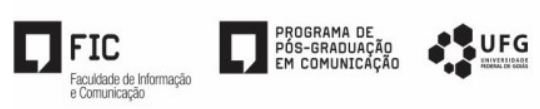

internautas que reagiram criticando o trabalho da imprensa, a dramatização da notícia e a opacidade das babás dentro da construção midiática do fato.

Algumas matérias sequenciais comentavam que Luciano e Angélica estavam se submetendo à terapia psicológica em razão do trauma do acidente. Diversos posts nas redes sociais e em blogs de comunicação questionaram onde estava a preocupação com o lado psicológico das babás (que permaneceram sem nome na mídia) e se o depoimento delas e seus sentimentos em relação ao caso não merecia ser igualmente colocado.

Neste caso, é possível fazer uma leitura do incômodo em relação à cultura do notório que começa a vir à tona por meio dos canais livres de expressão da internet. As queixas de diversos internautas demonstram a indignação com o olhar excludente do jornalismo em sua maioria e a indução a uma reflexão dos acontecimentos sociais fora das fórmulas capitalistas de vendas.

Levy e Lemos (2010) em suas otimistas constatações sobre a internet já declaravam o papel significativo para a liberdade de expressão que seria possibilitada com a liberação da palavra. Para os autores novos interlocutores poderiam falar a grandes públicos e assim exercer influência e ameaçar a hegemonia discursiva da mídia tradicional, lançando recortes e interpretações determinantes para o debate público, especialmente para a formação da opinião pública.

\section{CONCLUSÃO}

Ao avaliar a trajetória histórica da humanidade e de suas sociedades é fácil constatar que a comunicação foi o viés viabilizador que promoveu a integração dos indivíduos e o estabelecimento das organizações comunitárias. As proeminentes lideranças emergiram dentro de cada sociedade e encontraram meios de se sobressair em relação aos demais, exercendo controle e poder. No decorrer do tempo, a imprensa nasce oficialmente na Europa e permite novas interlocuções sociais que desembocaram em melhorias públicas e em ganhos para a cidadania.

O paradoxo se abre quando esta imprensa que surge como ferramenta redentora dentro das sociedades, se embaralha nas mazelas capitalistas e se apropria do discurso de controle que contraditoriamente passa a prejudicar as noções sociais que ajudou a salvar anteriormente. Ao aderir a lógica mercadológica aparecem nas empresas jornalísticas técnicas cada vez mais voltadas a indução do consumo e cada vez mais desvencilhadas de objetivos comunitários e 


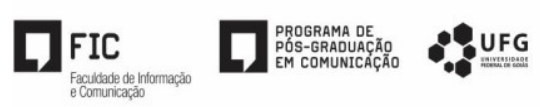

plurais.

Os critérios de noticiabilidade, em especial a notoriedade, representam neste artigo uma das estratégicas comerciais para agilizar o processo de reconhecimento e fabricação da notícia, e a industrialização das informações que constroem a opinião pública. Apesar de haver neste texto um enfoque nesta técnica específica, que demonstra a hierarquia de pessoas na estruturação das notícias, é sabido que muitas outras também estão anexas no rol jornalístico.

Essa reflexão direciona para uma revisão das diretrizes curriculares dos cursos de Jornalismo, para que seja possível atualizar conceitos e incluir nos discentes uma fundamentação ética, técnica, estética, teórica e que acima de tudo contribuam para qualificar o exercício e contribuir com a sociedade.

Por esta razão, instituições como a Universidade Federal de Goiás tem buscado atualizar as matrizes dos cursos de Jornalismo, elevando seu papel humanística, preparando o indivíduo para questionar, refletir e sempre empreender o ganho social naquilo que executar na profissão. A ideia é que sendo o jornalista os olhos que capturam os fatos para transmitir em forma de verdades, bem como uma opinião pública, é preciso extirpar a miopia que bloqueava a ótima social da atividade jornalística, frisando ao profissional apenas o ganho imediato. Não basta apenas contar com um ou outro módulo de disciplinas reflexivas como Sociologia, Filosofia ou Antropologia e uma sobrecarga de conteúdos e práticas que inviabilizam um trabalho autônomo e com propósito ético e igualitário.

No projeto pedagógico do curso, aprovado em novembro de 2015, a proposta é modificar as matrizes disciplinares que envolvem a formação do estudante de Jornalismo, para que este possa desenvolver nos discentes uma maior autonomia, valorização da ética e reflexão consciente acerca das atualizações sociais, com efetivo enfoque na cidadania. Entre os aspectos fundamentais esta a busca pela inserção da polifonia nos meios de comunicação e uma concreta discussão sobre os processos de regulação que envolvem a área e as diversas outras que acabam por se envolver com o trabalho da mídia. (DIAS, 2015)

Não se trata de negligenciar o objetivo comercial das empresas de comunicação mas buscar a sustentabilidade destes meios com os anseios sociais da atualidade. Sempre haverão notícias com maior atratividade em relação à outras, mas não é pertinente que a morte de um elemento tido como "célebre" por sua condição social ou status seja expressa com tamanha 


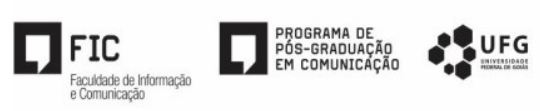

dissonância da morte de qualquer outro ser humano.

A idolatria midiática nasce na própria composição do profissional que subverte os princípios éticos em detrimento dos intuitos empresariais, ou que admitidos no mercado ficam reféns das técnicas e coordenadas da profissão. Sabendo que ao ingressar no curso de Jornalismo, o calouro se predispõe a aprender a reconhecer as notícias e ler o mundo com suas lentes profissionais, basta que se tenha a ousadia de modificar esse processo de aprendizado e apreensão, incluindo nesta etapa de formação valores e técnicas que consigam ir além das irrisórias categorias de atuação, chegando quem sabe a formação de líderes de opinião conscientes aptos a articular de modo favorável e integralista em seu percurso de trabalho.

Longe de uma ótica puramente ingênua que desconsidere o direcionamento capitalista dentro da prática do jornalismo, a provocação que se faz é na capacidade de induzir um pensamento crítico da atuação frente aos parâmetros éticos. Fatalmente permaneceram inseridos na comunicação padrões valorativos que elejam como prioridade a lucratividade do veículo, como é o caso dos valores-notícia. Todavia, a inserção desta reflexão dentro do próprio ambiente de formação do jornalista pode representar uma procura por coberturas mais isonômicas, ainda que existam marcas de celebridades e notoriedade.

O ranço financeiro na condução jornalística parece instransponível se não levarmos em conta que muito da mentalidade social foi transformada a partir de produtos midiáticos que se adaptaram às exigências do contexto. Penna (2006) já asseverava isso ao comentar o ingresso da temática social e ambiental dentro das preocupações da mídia. Segundo o autor, é fato que acidentes como Chernobyl foram determinantes para emplacar a preocupação ambiental dentro da mídia. Todavia, o autor comenta que a própria mídia precisou se abrir em diálogo com a ciência e gradualmente incluir um novo olhar jornalístico no tratamento das notícias que sancionou uma mudança de olhar dentro da própria sociedade por meio da opinião pública.

Certamente, o meio ambiente ou a responsabilidade social ainda não disputam a seleção em igualdade com matérias com maior relevância política e econômica, contudo a presença delas já demonstra uma abertura significativa da comunicação como um todo, e seu efeito na mentalidade dos públicos. Diante das conclusões deste artigo, a esperança é de que isso se amplie para fatores que incluam a percepção da diversidade, da pluralidade e da própria cidadania. A proposta de humanização das narrativas jornalísticas abre caminho para um avanço neste sentido. 
(MEDINA, 1995)

A prática jornalística já se tornou lugar-comum na sociedade e seu desempenho algumas vezes pernicioso e discriminatório passa despercebido por já ser familiarizado com a noção de imprensa na qual as pessoas se acostumaram. Neste momento, o importante seria fazer como propunha da Matta (1978) um estranhamento, tornando o familiar, exótico para que se enxergue o exótico como familiar.

\section{REFERENCIAS}

AVIÃO com Angélica e Luciano Huck sofre acidente e faz pouso forçado. Correio 24 horas, São Paulo, 2015. Disponível em: $<$ http://www.correio24horas.com.br/detalhe/noticia/aviao-com-angelica-e-lucianohuck-sofre-acidente-e-faz-pouso-forcado/?cHash=915d73829ebb21a65776ba342ff4445c $>$. Acesso em: set. 2015.

AVIÃO com Luciano Huck, Angélica e filhos faz pouso forçado em MS. Folha de São Paulo, São Paulo, 2015. Disponível: $<$ http://www1.folha.uol.com.br/cotidiano/2015/05/1633115-aviao-com-luciano-huckangelica-e-filhos-faz-pouso-forcado-em-ms.shtml>. Acesso em: set. 2015.

BACELAR, C. Filho de Ivo Pitanguy recebe alta e é levado a penitenciária de Bangu. Estadão, Rio de Janeiro, 2015. Disponível: $<$ http://brasil.estadao.com.br/noticias/rio-de-janeiro,filho-de-ivo-pitanguyrecebe-alta-e-e-levado-a-penitenciaria-de-bangu,1749224>. Acesso em: set. 2015.

BACELAR, C. Homem morre após se atropelado por carro do filho de Ivo Pitanguy. O Estado de São Paulo, São Paulo, 2015. Disponível em: $<$ http://brasil.estadao.com.br/noticias/rio-de-janeiro,homemmorre-apos-ser-atropelado-por-carro-do-filho-de-ivo-pitanguy,1748330>. Acesso em: set. 2015.

BENITES, F. Na política, Renata Campos vai além do papel figurativo. Jornal do Commercio, Pernambuco, 2015. Disponível em: $<$ http://jconline.ne10.uol.com.br/canal/politica/pernambuco/noticia/2015/03/08/na-politica-renatacampos-vai-alem-do-papel-figurativo-171250.php>. Acesso em: set. 2015.

BERGAMO, M. Filho de Alckmin é um dos cinco mortos em queda de helicóptero em SP. Folha de São Paulo, São Paulo, 2015. Disponível em:<http://www1.folha.uol.com.br/cotidiano/2015/04/1611998-filhode-alckmin-e-um-dos-cinco-mortos-em-queda-de-helicoptero-em-sp.shtml>. Acesso em: Acesso em: set. 2015.

BONATO, G. Candidato à Presidência Eduardo Campos morre em acidente de avião. O Estado de São Paulo, , Rio de Janeiro, 2015. Disponível em: $<$ http://www.estadao.com.br/noticias/geral,candidato-apresidencia-eduardo-campos-morre-em-acidente-de-aviao,1543188>. Acesso em: Acesso em: set. 2015.

BRESSER, D. As babás sem nome dos filhos de Angélica e Luciano Huck. Blog da DB, Rio de Janeiro, 2015. Disponível em: < http://entretenimento.r7.com/blogs/blog-da-db/as-babas-sem-nome-dos-filhos-deangelica-e-luciano-huck-20150526/> . Acesso em: set.2015.

Comun. \& Inf., Goiânia, GO, v. 18, n. 02, p. 217-235, jul./dez. 2015

Caderno Casadinho Procad UFG-UFRJ 
CAMBRICOLI, F.; DIOGENES, J. Avião que levava Angélica e Luciano Huck faz pouso forçado em fazenda de MS. O Estado de São Paulo, São Paulo, 2015. Disponível

em: $<$ http://brasil.estadao.com.br/noticias/geral,aviao-que-levava-angelica-e-luciano-huck-faz-pousoforcado-em-fazenda-de-ms, 1693330>. Acesso em: set. 2015.

CANEVACCI, M. A cidade polifônica: ensaio sobre a antropologia da comunicação urbana. 2. ed. São Paulo: Studio Nobel, 2004.

COMO se chamam as babás dos filhos de Huck e Angélica. Pragmatismo Político, São Paulo, 2015. Disponível em: $<$ http://www.pragmatismopolitico.com.br/2015/05/como-se-chamam-as-babas-dos-filhosde-huck-e-angelica.html>. Acesso em: set. 2015.

COSTA, F. B. Garis: um estudo de psicologia sobre invisibilidade pública. 2002. 177 f. Dissertação (Mestrado em Ciências Humanas, Psicologia) - Universidade de São Paulo, São Paulo, 2002.

DA MATTA, R. O ofício de etnólogo, ou como ter "Anthropological Blues". In: NUNES, E. O. (Org.). A aventura sociológica: objetividade, paixão, improviso e método na pesquisa social. Rio de Janeiro: Zahar Editores, 1978. p. 23-35.

DIAS, L. O. Desatando nós e construindo laços: dialogicidade, comunicação e educação. In. VIDAL, R,; MELO, J, M,; MORAIS, O. J. (Orgs.). Teoria da comunicação: correntes de pensamento e metodologia de ensino. São Paulo: Intercom, 2014.

DIAS, L. O. Projeto pedagógico do curso de jornalismo. Goiânia: UFG, 2015.

EDUARDO Campos morre em acidente aéreo em Santos. O Globo, São Paulo, 2014. Disponível em: $<$ http://oglobo.globo.com/brasil/eduardo-campos-morre-em-acidente-aereo-em-santos-1-13586260>. Acesso em: set. 2015.

FANTTI, B. Filho de Ivo Pitanguy é preso após atropelar e matar operário do metrô. Folha de São Paulo, São Pauo, 2015. Disponível e: <http://www1.folha.uol.com.br/cotidiano/2015/08/1671985-filho-de-ivopitanguy-e-preso-apos-atropelar-e-matar-operario-do-metro.shtml>. Acesso em: set. 2015.

FERREIRA. F. Filho de Alckmin é enterrado sob comoção em Pindamonhangaba. Folha de São Paulo, São Paulo, 2015. Disponível em: $<$ http://www1.folha.uol.com.br/cotidiano/2015/04/1612231-filho-dealckmin-e-enterrado-sob-comocao-em-pindamonhanga.shtml>. Acesso em: set. 2015.

FIGUEIREDO, L. M. F.; TUZZO, S. A. Célebre sociedade. Goiânia: Kelps. 2011.

FILHO de Alckmin morre em queda de helicóptero na Grande São Paulo. UOL Notícias, São Paulo, 2015. Disponível em: $<$ http://noticias.uol.com.br/cotidiano/ultimas-noticias/2015/04/02/filho-de-alckminmorre-em-queda-de-helicoptero-na-grande-sao-paulo.htm>. Acesso em: set. 2015.

FILHO de cirurgião se envolve em acidente com um morto no RJ. Produção de Rede TV. Rio de Janeiro. Disponível em: $<$ http://www.redetv.uol.com.br/jornalismo/redetvnews/videos/cidades/filho-de-cirurgiaose-envolve-em-acidente-com-um-morto-no-rj>. Acesso em: set. 2015.

FILHO de Ivo Pitanguy acumula 70 multas de trânsito; 14 são por embriaguez. R7 Notícias, Rio de

Comun. \& Inf., Goiânia, GO, v. 18, n. 02, p. 217-235, jul./dez. 2015

Caderno Casadinho Procad UFG-UFRJ 
Janeiro, 2015. Disponível em: $<$ http://noticias.r7.com/rio-de-janeiro/filho-de-ivo-pitanguy-acumula-70multas-de-transito-14-sao-por-embriaguez-21082015>. Acesso em: set. 2015.

GORZEVSCKI, C.; MARTIN, N. B. A necessária revisão do conceito de cidadania: movimentos sociais e novos protagonistas na esfera pública democrática. Santa Cruz do Sul, RS: EDUNISC, 2011.

HAIDAR, D. Thomaz Alckmin é enterrado em Pindamonhangaba. Revista Veja, São Paulo, 2015. Disponível em: $<$ http://veja.abril.com.br/noticia/brasil/thomaz-alckmin-e-enterrado-empindamonhangaba/>. Acesso em: set. 2015.

HERDY, T. [et. al.] O Globo, São Paulo, 2015. Disponível em:<http://oglobo.globo.com/brasil/filho-dogovernador-de-sao-paulo-morre-em-acidente-aereo-15768796>. Acesso em: set. 2015.

HOSPITAL que atendeu Angélica e Huck negou leitos para pacientes do Samu. O Povo Online, São Paulo, 2015. Disponível

em:<http://www.opovo.com.br/app/maisnoticias/brasil/2015/05/27/noticiasbrasil,3444437/hospital-queatendeu-angelica-negou-leitos-para-pacientes-do-samu.shtml>. Acesso em: set. 2015.

http:/noticias.terra.com.br/brasil/politica/marina-silva-ganha-forca-como-possivel-candidata-apos-mortede-eduardo-campos,91b665e9dead7410VgnCLD200000b1bf46d0RCRD.html>. Acesso em: set. 2015.

LAGO, C. Reflexões sobre antropologia e comunicação: o ethos romântico do jornalismo e enquanto um estudo de caso. In: TRAVANCAS, I.; FARIAS, P. (Orgs.). Antropologia e Comunicação. Rio de Janeiro: Garamond, 2003.

LEMOS, A.; LÉVY, P. O futuro da internet: em direção a uma ciberdemocracia planetária. São Paulo: Paulus, 2010.

LUCIANO Huck, Angélica e os filhos recorrem à terapia após acidente de avião. Pure People, São Paulo, 2015. Disponível em: $<$ http://www.purepeople.com.br/noticia/luciano-huck-angelica-e-os-filhos-recorrema-terapia-apos-acidente-de-aviao_a58046/1>. Acesso em: set. 2015.

MEDINA, C. A. Entrevista: O diálogo possível. São Paulo: Ática,1995.

MORGADO, I. S. A pressão política sobre os líderes de opinião. In. CORREIA, J. C. (Orgs.).

Comunicação e política: estudos de comunicação. Covilhã (Portugal): Universidade da Beira Interior, 2005.

PENNA, R. B. Cultura: um conceito antropológico. 19. ed. Rio de Janeiro: Jorge Zahar, 2006.

PINSKY, J.; PINSKY, C. B. História da cidadania. São Paulo: Editora Contexto, 2008.

PRESIDENCIÁVEL Eduardo Campos morre em acidente aéreo em Santos (SP). Folha de São Paulo, São Paulo, 2014. Disponível em:<http://www1.folha.uol.com.br/poder/2014/08/1499718-presidenciaveleduardo-campos-morre-em-acidente-aereo-em-santos-sp.shtml>. Acesso em: set. 2015.

SANTOS, B. S. Introdução a uma ciência pós moderna. Rio de Janeiro: Graal, 1989.

SANTOS, E. Forte comoção marca o adeus a Thomaz Alckmin. O Vale, São Paulo, 2015. Disponível

Comun. \& Inf., Goiânia, GO, v. 18, n. 02, p. 217-235, jul./dez. 2015

Caderno Casadinho Procad UFG-UFRJ 


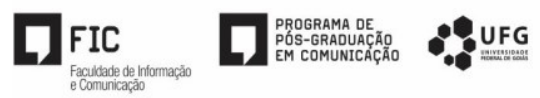

em: $<$ http://www.ovale.com.br/forte-comoc-o-marca-o-adeus-a-thomaz-alckmin-1.581174>. Acesso em: Acesso em: set. 2015.

SODRÉ, N. W. História da imprensa no Brasil. 4. ed. São Paulo: Mauad, 1999.

TRAQUINA, N. Teorias do jornalismo: porque as notícias são como são. 2. ed. Florianópolis, SC:

Insular, 2005. v. 1

TUZZO, S. A. Deslumbramento coletivo: opinião pública, mídia e universidade. São Paulo: Editora Annablume, 2005.

TUZZO, S. A.; BRAGA, C. F. Representações sociais e opinião pública: interfaces conceituais. Revista Anhanguera, Goiânia,GO, v.10 n.1 jan./dez. p.135-150, 2009.

WOLF, M. Teorias da comunicação de massa. Lisboa: Presença, 2001.

XUXA e famosos lamentam morte do filho de Geraldo Alckmin: 'Sinta-se abraçada'. Pure People, São Paulo, 2015. Disponível em: $<$ http://www.purepeople.com.br/noticia/xuxa-e-famosos-lamentam-morte-dofilho-de-geraldo-alckmin-sinta-se-abracada_a49962/1>. Acesso em: set. 2015.

Comun. \& Inf., Goiânia, GO, v. 18, n. 02, p. 217-235, jul./dez. 2015

Caderno Casadinho Procad UFG-UFRJ 